Revista de

Contabilidade e

Organizações

www.rco.usp.br
DOI: http://dx.doi.org/10.11606/rco.v9i25.97726
Journal of

Accounting and

Organizations

www.rco.usp.br

\title{
O impacto do nível de disclosure sobre o custo de capital próprio das companhias abertas brasileiras
}

Davy Antonio da Silva ${ }^{a}$; Laura Edith Taboada Pinheiro ${ }^{b}$

${ }^{a}$ Universidade Federal de Uberlândia

${ }^{b}$ Universidade Federal de Minas Gerais

\section{Informações do Artigo}

Histórico do Artigo

Recebido: 04 de maio de 2015

Aceito: 03 de dezembro de 2015

\section{Palavras chave:}

Custo de Capital Próprio.

Dados em Painel.

Disclosure.

IFRS.

\section{INTRODUÇÃO}

\begin{abstract}
Resumo
O objetivo deste estudo foi analisar o nível de disclosure e sua relação com o custo de capital próprio das empresas de capital aberto, após a conversão das normas contábeis brasileiras para os IFRS. A principal teoria utilizada para sustentar os achados desta pesquisa quanto ao nível de disclosure foi a Teoria da Divulgação, demonstrando também a importância das informações contábeis para os seus diversos usuários. A pesquisa foi orientada através de uma análise descritiva e explicativa, na qual foram analisadas 66 empresas entre os anos de 2005 até 2011, sendo calculado o custo de capital e o índice de disclosure para cada organização. Aplicou-se o método de regressão com dados em painel, com a finalidade de escolher um, dentre os três principais modelos, Pooled, Efeitos Fixos e Efeitos Aleatórios, que fosse mais adequado para demonstrar se e de que forma o nível de disclosure afeta no custo de capital das empresas. Os resultados encontrados demonstram que não existem evidências estatísticas de que o nível de disclosure tem relação com o custo do capital, após a conversão para as normas internacionais de contabilidade.
\end{abstract}

Copyright (C) 2015 FEA-RP/USP. Todos os direitos reservados

O movimento visando à adoção das normas internacionais de contabilidade pelo Brasil pode ser explicado por diversos aspectos. Dentre eles, destacam-se a redução das taxas inflacionárias e a expansão do mercado de capitais, aumentando a importância da informação contábil como subsídio para as decisões de investimentos, créditos, financiamentos etc. Entretanto, as diferenças entre as práticas contábeis locais e internacionais mostraramse um problema para fomentar tais investimentos no país.

Assim sendo, o Brasil passou a adotar as normas emitidas pelo International Accounting Standard Board (IASB), mais comumente conhecidas como International Financial Reporting Standards (IFRS), que trouxe como principal inovação fazer com que a prática contábil brasileira passe a estar muito mais baseada na interpretação dos pronunciamentos do Comitê de Pronunciamentos Contábeis (CPC) do que na mera aplicação de regras nacionais, como no passado recente. Isso traz implicações relevantes para a qualidade da informação contábil divulgada para o profissional da contabilidade e para outros profissionais que utilizam essa informação tais como: investidores, analistas do mercado financeiro e para outros interessados.

Na tentativa de amenizar esses problemas, Silva, Reis e Lamounier (2012) descrevem que a implantação de boas práticas de governança corporativa tem se mostrado a principal ferramenta de conciliação entre os interesses dos investidores e os das empresas, sendo esta vista como uma alternativa adicional ao controle e fiscalização das ações executadas pelos gestores.

Nos últimos anos, no Brasil, esse tema é recorrente no meio acadêmico e profissional, e, de acordo com Andrade et al. (2009), é estudado tanto em países desenvolvidos quanto nos emergentes. Nesses países, como o Brasil, o desenvolvimento do mercado, a abertura econômica, a reestruturação societária provocada pelas privatizações e a entrada de novos acionistas no mercado privado exigiram das empresas maiores e melhores práticas de direção para satisfazer as relações, principalmente, entre acionistas majoritários e minoritários.

Autor Correspondente: Tel (34) 3239-4411

E-mail:davyantonio@yahoo.com.br (D. A. Silva); ltaboada@face.ufmg.br (L. E. T. Pinheiro);

Universidade Federal de Uberlândia - Av. João Naves de Ávila, 2121 - Santa Mônica, Uberlândia - MG, 38408-100 
A ligação entre disclosure e custo de capital próprio tem origem no fenômeno da seleção adversa descrito por Akerlof (1970). Ao divulgar informações contábeis, conforme Alencar (2007), a empresa reduz a assimetria informacional entre emissores de ações ordinárias e investidores, afetando a habilidade dos participantes do mercado em realizar estimativas acerca da distribuição dos fluxos de caixa futuros.

Sendo assim, a disponibilidade de informação diminui o grau de incerteza dos investidores a respeito dos fluxos futuros de caixa, reduzindo o componente relativo ao risco de estimativa na taxa utilizada para trazer tais fluxos ao valor presente.

Diante do exposto, apresenta-se a seguinte questão problema: as empresas brasileiras de capital aberto estão divulgando suas informações de forma que afetem o custo de capital após a convergência para os IFRS?

O presente estudo tem como objetivo analisar o nível de disclosure e sua relação com o custo de capital de terceiros e o custo de capital próprio das empresas de capital aberto, após a convergência das normas contábeis brasileiras para os IFRS.

Este trabalho está pautado na seguinte hipótese de pesquisa: o nível de disclosure das empresas de capital aberto não impacta o custo de capital de terceiros e próprio após a adoção das normas internacionais de contabilidade.

A justificativa desta pesquisa está fundamentada nas pesquisas de Alencar (2005) e Lima (2009). Para esses autores, as empresas brasileiras são fortemente influenciadas pelas transformações e exigências do mercado, em que as companhias brasileiras buscam por um maior nível de disclosure e, como consequência, conseguem uma vantagem em relação aos seus concorrentes.

Outro aspecto que deve ser ressaltado é o fato de que, apesar de existirem trabalhos na literatura que abordem as questões da divulgação das informações contábeis e a redução do custo de capital, não existem estudos no Brasil que analisam a relação do disclosure após a convergência das normas contábeis brasileiras aos IFRS. Espera-se, com a realização deste estudo, verificar se a adoção dos IFRS no Brasil trouxe redução do custo de capital das companhias listadas na bolsa, contribuindo, assim, para a literatura nacional, além de ressaltar o interesse em demonstrar os benefícios econômicos diretos no que tange ao nível de evidenciação.

Para a contabilidade, os resultados da presente pesquisa contribuem para um melhor entendimento da relação entre disclosure e custo de capital, e os efeitos da adoção de um padrão contábil que busca apresentar melhor a realidade das transações e situação das empresas orientando os seus diversos usuários em suas ações de tomada de decisão e comunicação com o mercado.

Este artigo está estruturado em cinco seções. Além da introdução, é contemplada no tópico 2 uma revisão de literatura, a seção 3 traz os procedimentos metodológicos para elaboração da pesquisa, a seção 4 relata os resultados e as discussões e a seção 5 traz a conclusão com sugestões para realização de pesquisas futuras, sendo finalizado com as referências bibliográficas utilizadas.

\section{REFERENCIAL TEÓRICO}

\subsection{Teoria da Divulgação}

A Teoria da Divulgação se forma como um campo de estudo positivo da contabilidade nas décadas finais do século XX e contrapõe a contabilidade normativa em relação à metodologia e objetivos, ao se basear em evidências empíricas e modelos de análise advindos da teoria econômica para explicar e predizer a realidade. O principal objetivo da Teoria da Divulgação é explicar o fenômeno da divulgação das informações financeiras (ROVER; BORBA; MURCIA, 2009).

O ambiente da divulgação financeira, conforme Yamamoto e Salotti (2006), em uma empresa com ótimas perspectivas financeiras para os próximos três anos tem um incentivo maior para demonstrar seus detalhes, acreditando que os custos relacionados a essa divulgação serão compensados pelos benefícios, porque a não divulgação dessa informação levará o mercado a interpretar que as perspectivas financeiras dos próximos anos serão ruins. Por outro lado, se as perspectivas financeiras da empresa serão ruins, não adiantará incorrer em custos de divulgação dessa informação, pois, na ausência da divulgação, o mercado já terá essa interpretação de 
dificuldade futura da empresa.

Verrecchia (2001), afirma sobre a inexistência de uma teoria unificada da divulgação, uma vez que na literatura da pesquisa sobre divulgação não há nenhum paradigma central, nem uma única noção convincente que dá origem a todas as pesquisas subsequentes, nenhuma "teoria" bem integrada. Essa posição é contestada por Dye (2001), que afirma ser esta teoria, que ele delimita como Teoria da Divulgação Voluntária, um caso especial da Teoria dos Jogos, com a premissa central de que a entidade irá divulgar informações favoráveis, ao mesmo tempo em que não evidenciará informações desfavoráveis. De qualquer modo, ambos os autores trabalham com a taxionomia dos trabalhos em Teoria da Divulgação, criada por Verrecchia (2001):

a) Divulgação baseada na associação: a principal característica desse tipo de pesquisa é o estudo dos efeitos da divulgação nas mudanças das ações dos investidores, principalmente através do comportamento dos preços dos ativos em equilíbrio e do volume de negociação (SALOTTI e YAMAMOTO, 2005). Nesses trabalhos, a divulgação é considerada exógena, ou seja, ela não é uma das variáveis a serem explicadas (ROVER; BORBA; MURCIA, 2009).

b) Divulgação baseada em julgamento: abrange as pesquisas que tentam explicar os motivos da divulgação, considerando o comportamento dos agentes que divulgam (empresas e/ou administradores) e dos que recebem (investidores ou mercado financeiro como um todo). Desse modo, o processo de divulgação é endógeno ao modelo de análise, e a informação já existe, sendo conhecida pela entidade divulgadora, o que a torna ex post em relação ao momento da divulgação (SALOTTI e YAMAMOTO, 2005; ROVER, BORBA e MURCIA, 2009);

c) Divulgação baseada na eficiência: abrange pesquisas sobre quais configurações de divulgação são as preferidas, na ausência de conhecimento passado sobre a informação, isto é, a divulgação ainda não ocorreu. Nesse caso, as ações dos agentes do mercado de capitais que maximizam a riqueza são endógenas (SALOTTI e YAMAMOTO, 2005).

Diante disso, e conforme já ressaltado anteriormente, Verrechia (2001) afirma que as empresas procuram um equilíbrio no qual a informação que a favorece é evidenciada, enquanto a que a desfavorece não é evidenciada e que a entidade tende a divulgar voluntariamente apenas informações positivas e, dessa forma, Dye (2001) afirma que a divulgação de informações financeiras, consideradas de natureza voluntária, pode refletir o custo de capital das empresas.

\subsection{A importância da evidenciação das informações contábeis}

Conforme Deegan e Rankin (1997), Cormier, Gordon e Magnan (2004), Hasseldine, Salama e Toms (2005) e Tilt (2001), a evidenciação contábil é vista, sob a ótica construtivista, como um processo em que empresa e sociedade permanecem em constante comunicação e aprendizagem sobre suas causas, efeitos, formas de controle e comprometimento de ambos em uma visão sociopolítica.

O trabalho de Dias Filho (2000) discutiu a utilidade da informação contábil e o termo evidenciação que permeia as principais reflexões, pois este se identifica com os próprios objetivos da contabilidade, caracterizandose como o meio pelo qual esta deve cumprir a sua missão, que é comunicar aos seus usuários informações relevantes para orientar decisões.

A pesquisa de Ponte et al. (2007) conclui que as empresas brasileiras ainda têm muito a evoluir no sentido da transparência e qualidade da divulgação das demonstrações contábeis. Contudo, a pesquisa indica, também, que o apelo da sociedade no sentido da adoção de boas práticas de governança corporativa parece estar influenciando o comportamento das organizações, as quais já incluem no corpo de suas demonstrações contábeis publicadas um maior volume de informações de natureza avançada e não obrigatória.

Soares (2001) investigou a qualidade das demonstrações contábeis das empresas brasileiras, destacando uma mudança de comportamento das organizações de capital aberto que passaram a dar nova roupagem a seus balanços, depois de negociar ações no mercado norte-americano. Segundo o autor, as empresas sofisticaram os seus balanços, apresentando informações apreciadas pelas boas práticas de relacionamento com o mercado.

\subsection{Custo de Capital Próprio}


O custo de capital próprio, de acordo com Silva e Quelhas (2006), é a taxa de retorno mínima requerida pelos investidores ao realizar um determinado investimento, estando esta associada ao custo de oportunidade que um investidor teria ao aplicar em um investimento alternativo equivalente.

Dentre as diversas pesquisas sobre o custo de capital próprio destaca-se a de Bruni (2002), que examinou o comportamento das ações das empresas brasileiras emissoras de ADR, no período 1992 a 2001, evidenciando uma significativa redução do custo de capital próprio, expressado pela variação negativa dos betas das ações, após a emissão dos ADRs. Adicionalmente, Bruni (2002) realizou o estudo de eventos, evidenciando a presença de: retornos anormais maiores no período anterior ao evento; anormais significativos e positivos em torno do evento; e negativos no período posterior, corroborando as evidências de reduções nos níveis do custo de capital.

Alencar e Lopes (2005) investigaram, através de regressões com variáveis qualitativas, o quanto o nível de evidenciação influencia o custo do capital próprio nas empresas negociadas no mercado brasileiro. Nesse estudo, os pesquisadores utilizaram o beta das empresas como representação da variável custo de capital e a nominação das empresas para o prêmio transparência da Associação Nacional dos Executivos de Finanças, como representação de um nível de disclosure. Esses pesquisadores chegaram a resultados contrários a outras pesquisas, percebendo que o nível de disclosure não afeta o custo de capital próprio das empresas.

Nakamura et al. (2006) estudaram a associação existente entre disclosure e custo de capital próprio de companhias abertas brasileiras através de regressões. Como variável dependente, adotou-se o custo de capital e, como variáveis explicativas, foram analisados três índices de disclosure e nove variáveis indicativas de tamanho, risco e variabilidade dos resultados. Para o cálculo do custo de capital, foram utilizados três modelos: o Modelo de Precificação de Ativos de Capital (CAPM), o de Dividendos Descontados (MDD) e o de Ohlson e Juettner. Os resultados dessa pesquisa evidenciaram que o modelo escolhido para cálculo do custo de capital interfere nos resultados obtidos nos testes empíricos, e que a variável disclosure pode se apresentar significativa em um modelo e não significativa em outro. Segundo os autores, esses resultados estão em concordância com os dados obtidos pelo estudo de Botosan realizado no ano de 1997.

\section{PROCEDIMENTOS METODOLÓGICOS}

\subsection{Unidade de análise e coleta de dados}

O estudo foi realizado com as empresas listadas na Bolsa de Mercadorias e Futuros e da Bolsa de Valores de São Paulo (BM\&F BOVESPA). O método de seleção da amostra considerou todas as empresas que compõem o índice IBrx 100, as quais representam as 100 maiores companhias listadas na bolsa.

Os dados das companhias selecionadas utilizados para as variáveis de controle foram extraídos dos Demonstrativos Contábeis Consolidados referentes aos exercícios financeiros anuais, do período de 2005 a 2011 , através do site da BOVESPA, do banco de dados Economática e do site das empresas que fazem parte da amostra.

\subsection{Modelo utilizado para o cálculo do custo de Capital Próprio}

Para o Cálculo do custo de Capital Próprio, dentre as abordagens existentes, é comumente aceito, no meio acadêmico, o modelo CAPM visto que, de acordo com Araújo, Lima e Assaf Neto (2008), apesar de existirem críticas quanto à sua simplicidade e eficiência, não há nenhum outro disponível na literatura financeira que responda a todas as críticas formuladas. O Custo de Capital Próprio, de acordo com o modelo CAPM, é obtido pela fórmula:

$$
K e=R f+\beta \times(R m-R f)
$$

Onde:

$K e=$ Custo de oportunidade do capital próprio;

$R f=$ Retorno de um investimento livre de risco; 
$\beta=$ Risco da empresa em relação ao risco de todo o mercado acionário sendo calculado para um período de 12 meses;

$R m=$ Taxa de retorno da carteira de mercado.

Para o cálculo do custo do capital próprio pelo método anteriormente relacionado, foram consideradas as seguintes variáveis:

a) como risco de mercado, utilizou-se a taxa de retorno do IBrx 100 dos anos selecionados;

b) para a taxa livre de risco, utilizou-se a taxa Selic, para os anos estudados, por essa apresentar menor variação ao longo do tempo;

c) o risco da empresa foi obtido pelo site Economática.

\subsection{Construção da variável Disclosure}

O nível de disclosure é, conforme Alencar (2007) e Lima (2007), uma variável não visualizada que envolve aspectos tanto objetivos, os quais descrevem a quantidade de informação evidenciada, bem como subjetivos, esses relacionados à qualidade dessa mesma informação. Conforme salientam esses autores, os pesquisadores têm dois caminhos a percorrer: construir um indicador ou basear-se em indicadores já existentes.

Esta pesquisa tem como finalidade analisar os modelos existentes propostos por Alencar (2007), o qual se baseou no índice estruturado por Botosan (1997) adaptado à realidade brasileira. O modelo proposto por Alencar (2007) é demonstrado no Quadro 1.

\begin{tabular}{|c|c|c|c|}
\hline Perguntas & INFORMAÇÕES GERAIS SOBRE A EMPRESA & Sim & Não \\
\hline 1 & $\begin{array}{l}\text { O Relatório faz uma descrição geral do negócio (o que faz, onde está } \\
\text { localizada, a que grupo empresarial pertence)? }\end{array}$ & & \\
\hline 2 & Há descrição das principais metas corporativas para o futuro? & & \\
\hline 3 & $\begin{array}{c}\text { As metas estão expressas de forma quantitativa (quantidades, valores, } \\
\text { percentuais)? }\end{array}$ & & \\
\hline 4 & São descritos os principais mercados em que a empresa atua? & & \\
\hline 5 & Os mercados estão descritos de forma quantitativa? & & \\
\hline 6 & $\begin{array}{l}\text { São descritos os principais produtos ou serviços que a empresa } \\
\text { comercializa? }\end{array}$ & & \\
\hline 7 & Os produtos estão descritos de forma quantitativa? & & \\
\hline 8 & $\begin{array}{l}\text { O ambiente empresarial (conjuntura econômica relacionada ao setor de } \\
\text { atividade) em que a empresa atua é descrito? }\end{array}$ & & \\
\hline 9 & $\begin{array}{l}\text { Os negócios sociais e principais fatos administrativos (eventos mais } \\
\text { importantes) do período são descritos (exemplo: conquista de um } \\
\text { novo mercado, início de um programa de redução de desperdícios, } \\
\text { reestruturações internas, conclusão de nova fábrica, aquisição de novas } \\
\text { máquinas, entre outros)? }\end{array}$ & & \\
\hline 10 & Os eventos mais importantes estão descritos de forma quantitativa? & & \\
\hline Perguntas & RELAÇÕES COM EMPREGADOS E ADMINISTRADORES & Sim & Não \\
\hline 11 & A quantidade de empregados foi informada? & & \\
\hline 12 & $\begin{array}{c}\text { A remuneração média por empregado ou o gasto total com empregados } \\
\text { foi informado? }\end{array}$ & & \\
\hline 13 & $\begin{array}{l}\text { Os investimentos em treinamento e desenvolvimento gerencial estão } \\
\text { descritos de forma quantitativa? }\end{array}$ & & \\
\hline
\end{tabular}




\begin{tabular}{|c|c|c|c|}
\hline 14 & $\begin{array}{l}\text { Outras informações a respeito de empregados (turnover, grau de } \\
\text { satisfação, valor adicionado por empregado, produtividade, entre outros) } \\
\text { estão descritas de forma quantitativa? }\end{array}$ & & \\
\hline 15 & Existe informação a respeito da remuneração paga a administradores? & & \\
\hline Perguntas & $\begin{array}{l}\text { INFORMAÇÕES NÃO FINANCEIRAS SOBRE MERCADO, } \\
\text { VENDAS E PRODUTOS }\end{array}$ & Sim & Não \\
\hline 16 & A participação da empresa no mercado foi informada? & & \\
\hline 17 & $\begin{array}{l}\text { As vendas estão detalhadas por produto ou segmento de negócio (em } \\
\text { moeda, percentuais ou quantidades)? }\end{array}$ & & \\
\hline 18 & As vendas estão informadas em quantidade? & & \\
\hline 19 & $\begin{array}{l}\text { Foi informado o crescimento nas vendas em quantidade ou há uma série } \\
\text { histórica ( } 3 \text { ou mais anos) que permita calcular o crescimento? }\end{array}$ & & \\
\hline 20 & Os preços unitários de venda dos produtos foram informados? & & \\
\hline 21 & $\begin{array}{l}\text { Existe informação sobre novos produtos e serviços a serem lançados no } \\
\text { mercado? }\end{array}$ & & \\
\hline Perguntas & PROJEÇÕES & Sim & Não \\
\hline 22 & Informou vendas projetadas para o próximo exercício? & & \\
\hline 23 & Informou vendas projetadas para mais de um exercício? & & \\
\hline 24 & Informou lucros projetados para o próximo exercício? & & \\
\hline 25 & Informou lucros projetados para mais de um exercício? & & \\
\hline 26 & Informou fluxo de caixa projetado para o próximo exercício? & & \\
\hline 27 & Informou fluxos de caixa projetados para mais de um exercício? & & \\
\hline 28 & $\begin{array}{l}\text { Informou investimentos em pesquisas e desenvolvimento e outros ativos } \\
\text { intangíveis projetados? }\end{array}$ & & \\
\hline 29 & Informou participação de mercado projetada? & & \\
\hline Perguntas & DISCUSSÕES E ANÁLISE DE DADOS FINANCEIROS & Sim & Não \\
\hline 30 & Apresentou uma série histórica do valor das vendas (3 anos ou mais)? & & \\
\hline 31 & $\begin{array}{l}\text { Existe um comentário (explicações, justificativas) a respeito de } \\
\text { oscilações nas vendas? }\end{array}$ & & \\
\hline 32 & $\begin{array}{l}\text { Apresentou uma série histórica do custo dos produtos e serviços vendidos } \\
\qquad(3 \text { anos ou mais)? }\end{array}$ & & \\
\hline 33 & $\begin{array}{l}\text { Existe comentário (explicações, justificativas) a respeito de oscilações } \\
\text { nos custos dos produtos e serviços vendidos? }\end{array}$ & & \\
\hline 34 & Apresentou uma série histórica de lucros ( 3 anos ou mais)? & & \\
\hline 35 & $\begin{array}{l}\text { Existe comentário (explicações, justificativas) a respeito de oscilações } \\
\text { nos lucros? }\end{array}$ & & \\
\hline 36 & $\begin{array}{l}\text { Apresentou uma série histórica do valor das despesas administrativas e } \\
\text { comerciais ( } 3 \text { anos ou mais)? }\end{array}$ & & \\
\hline 37 & $\begin{array}{c}\text { Existe comentário (explicações, justificativas) a respeito de oscilações } \\
\text { nas despesas administrativas e comerciais? }\end{array}$ & & \\
\hline 38 & $\begin{array}{l}\text { Apresentou uma série histórica de receitas e despesas financeiras (3 anos } \\
\text { ou mais)? }\end{array}$ & & \\
\hline 39 & $\begin{array}{l}\text { Existe comentário (explicações, justificativas) a respeito de oscilações } \\
\text { nas receitas e despesas financeiras? }\end{array}$ & & \\
\hline 40 & $\begin{array}{c}\text { Declarou o montante dos investimentos feitos em pesquisas e } \\
\text { desenvolvimentos e outros ativos intangíveis? }\end{array}$ & & \\
\hline
\end{tabular}




\begin{tabular}{|c|c|c|c|}
\hline 41 & $\begin{array}{c}\text { Existe comentário (explicações, justificativas) a respeito de oscilações } \\
\text { em outro grupo de contas (contas a receber, estoques, receitas e despesas } \\
\text { não operacionais, entre outros)? }\end{array}$ & & \\
\hline Perguntas & OUTRAS INFORMAÇÕES & Sim & Não \\
\hline 42 & $\begin{array}{c}\text { Apresentou uma série histórica ( } 3 \text { anos ou mais) com percentual de } \\
\text { Retorno sobre Ativo Total (ROA)? }\end{array}$ & & \\
\hline 43 & $\begin{array}{c}\text { Apresentou uma série histórica ( } 3 \text { anos ou mais) com percentual sobre } \\
\text { Retorno sobre o Patrimônio Líquido (ROE)? }\end{array}$ & & \\
\hline 44 & Apresentou uma série histórica ( 3 anos ou mais) com Giro dos Ativos? & & \\
\hline 45 & Apresentou detalhamento de Cálculo dos Impostos? & & \\
\hline 46 & Apresentou Balanço Social ou Demonstração do Valor Adicionado? & & \\
\hline 47 & Apresentou Demonstração dos Fluxos de Caixa? & & \\
\hline 48 & A empresa pertence a algum nível de Governança Corporativa? & & \\
\hline
\end{tabular}

Quadro 1. Modelo de Disclosure proposto por Alencar (2007)

Fonte: Alencar (2007)

O índice desenvolvido por Alencar (2007) é composto por 47 perguntas e, a cada resposta "sim", foi atribuído um ponto e, para a resposta "não", a nota atribuída foi zero. De acordo com Alencar (2007), esse índice engloba seis dimensões de informação e, em cada dimensão, a nota obtida pela empresa foi apurada pela divisão entre a soma dos pontos obtidos e a pontuação total possível. Acrescentou ao modelo a pergunta de número 48 conforme demonstrado no Quadro 1.

\subsection{Variáveis de Controle utilizadas nos modelos}

As variáveis de controle necessárias para condução deste estudo e utilizadas para a elaboração da equação de regressão referentes ao custo de próprio foram classificadas em internas e externas.

As variáveis internas são:

a) O Nível de Endividamento (Nend), sendo esse determinado pela seguinte fórmula:

$$
N e n d=\frac{\text { Passivo Circulante total }+ \text { Exigivel a Longo Prazo total }}{\text { AtivoTotal }}
$$

b) Alavancagem (Alav), indicador visualizado de acordo com o procedimento abaixo:

$$
\text { Alav }=\frac{\text { Passivo }}{\text { Patrimônio Líquido }}
$$

c) Tamanho da Empresa (TE) calculado através do seguinte logaritmo neperiano:

$$
T E=\ln \text { Ativo Total }
$$

A escolha dessas variáveis se justifica pelo fato de que alterações em seus valores podem influenciar o custo de capital de terceiros, conforme descrito por Lima (2007), ou seja, essas variáveis estão diretamente ligadas ao valor referente ao custo de capital de terceiros das empresas que serão objeto deste estudo.

Como variáveis de controle externas foram utilizadas:

a) Produto Interno Bruto nos anos estudados $(P I B)$;

b) A taxa de inflação de cada ano (INF); 
A variável taxa de inflação utiliza como indicador o Índice Nacional de Preços ao Consumidor Amplo (IPCA) que utiliza em sua composição de cálculo, os seguintes setores: alimentação e bebidas, habitação, artigos de residência, vestuário, transportes, saúde e cuidados pessoais, despesas pessoais, educação e comunicação.

As variáveis $P I B$ e $I N F$ foram obtidas através dos dados disponibilizados pelo site do Banco Central do Brasil. A escolha dessas variáveis se partiu com a intenção de montar um modelo com indicadores brasileiros uma vez que o trabalho de Lima (2007) empregou a variável American Depositary Receipts (ADRs) que são recibos de depósito norte-americano, que representam ações de empresas estrangeiras, não negociáveis no país das empresas emissoras. Outro fato que justifica a adoção dessas variáveis é o fato de impactarem a estrutura do custo de capital das empresas de acordo com as variações provocadas na economia do país como descreve Soares e Funchal (2008).

Acrescentou-se ao modelo a variável dummy IFRS, a qual analisou se a empresa havia publicado suas demonstrações contábeis com a utilização das normas internacionais de contabilidade durante os anos pesquisados, sendo atribuído 1 para adoção do padrão das normas contábeis IFRS e 0 quando não se utilizou os IFRS para a elaboração dos demonstrativos financeiros.

\subsection{Efeito Esperado nas Variáveis de Controle utilizadas nos Modelos de Regressão}

O Quadro 2 apresenta um resumo das variáveis de controle utilizadas durante a elaboração das regressões para estimar o custo de capital próprio das empresas.

\begin{tabular}{c|c|c|c}
\hline Variáveis & Fonte & Resultado Encontrado & $\begin{array}{c}\text { Resultado } \\
\text { Esperado }\end{array}$ \\
\hline Índice de Disclosure (ID) & $\begin{array}{c}\text { Botosan e Plumlee } \\
(2001)\end{array}$ & Associação Negativa & $\begin{array}{c}\text { Espera-se uma Associação } \\
\text { Negativa }\end{array}$ \\
\hline $\begin{array}{c}\text { Nível de Endividamento } \\
\text { (Nend) }\end{array}$ & Lima (2007) & Associação Negativa & $\begin{array}{c}\text { Espera-se uma Associação } \\
\text { Negativa }\end{array}$ \\
\hline Alavancagem (Alav) & Alencar (2007) & Associação Negativa & $\begin{array}{c}\text { Espera-se uma Associação } \\
\text { Negativa }\end{array}$ \\
\hline Tamanho da Empresa (TE) & Hail (2002) & Associação Negativa & $\begin{array}{c}\text { Espera-se uma Associação } \\
\text { Negativa }\end{array}$ \\
\hline Produto Interno Bruto (PIB) & - & $\begin{array}{c}\text { Espera-se uma Associação } \\
\text { negativa }\end{array}$ & - \\
\hline Taxa de Inflação (TI) & - & $\begin{array}{c}\text { Espera-se uma Associação } \\
\text { negativa }\end{array}$ & negativa \\
\hline IFRS & - & $\begin{array}{c}\text { Espera-se uma Associação } \\
\text { nega }\end{array}$ & - \\
\hline
\end{tabular}

Quadro 2. Resultados esperados das variáveis de controle

Fonte: Elaborado pelos autores

\subsection{Hipóteses}

Com o intuito de verificar o relacionamento entre as variáveis anteriormente elencadas, apresenta-se, a fundamentação das hipóteses que estabelecem a relação entre o índice de disclosure e o custo de capital. O trabalho está pautado nas seguintes hipóteses para a estimação do custo de capital de terceiros e próprio das empresas que foram objetos deste estudo:

$H_{0}$ : o nível de disclosure não impacta no custo de capital após a convergência para os IFRS das empresas brasileiras de capital aberto;

$H_{1}$ : o nível de disclosure impacta no custo de capital após a convergência para os IFRS das empresas brasileiras de capital aberto, contribuindo para sua elevação;

$H_{2}$ : o nível de disclosure impacta no custo de capital após a convergência para os IFRS das empresas 
brasileiras de capital aberto, contribuindo para sua redução;

\subsection{Modelo de regressão utilizado para alcance dos resultados}

O modelo utilizado foi o de Regressão Linear Múltipla (MRLM) com dados cross-section. Conforme Stock e Watson (2004), o modelo de Regressão Linear Múltipla é uma ferramenta estatística utilizada para estimar efeitos sobre uma variável dependente, através da utilização de variáveis que possam explicar o seu comportamento (variáveis explicativas). No entanto, é importante destacar que um modelo estatístico é apenas uma aproximação da realidade e, portanto, incapaz de capturar todas as forças que estão agindo sobre a variável que se pretende estimar. Essas forças omitidas são as variáveis não observadas. Contudo, existe uma técnica de econometria para controlar essas variáveis omitidas, que é a regressão com dados em painel.

O método de dados em painel, de acordo com Gujarati e Porter (2011), trabalha com duas dimensões, sendo uma espacial (no caso deste estudo, as empresas), e outra, temporal. Com isso, o modelo consegue anular o efeito das variáveis que não podem ser observadas e que variam entre as entidades, mas que são constantes ao longo do tempo, reduzindo, assim, o viés de variável omitida.

O modelo utilizado para o cálculo do custo de capital próprio para estimação da regressão com dados em painel é representado por:

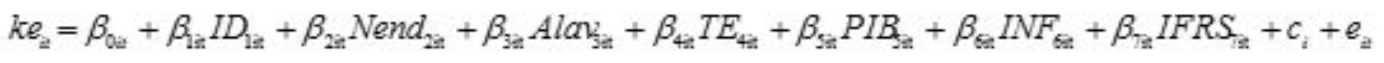

Onde:

$k e_{i t}$ representa o custo de capital próprio da empresa $i$ no período $t$;

$\beta_{\text {oit }}$ representa o coeficiente angular da regressão;

$\beta_{\text {lit }}$ representa o índice de disclosure como parâmetro a ser estimado pelo método dos mínimos quadrados ordinários;

$\beta_{2 i t}, \beta_{3 i t}, \beta_{4 i t}, \beta_{5 i t}$ e $\beta_{6 i t}$ representam os parâmetros a serem estimados pelo método dos mínimos quadrados ordinários;

$c_{i}$ : representa o efeito a ser estimado de uma variável não observada que varia entre as entidades;

$e_{i t}$ representa o termo de erro do modelo.

Para operacionalização dos modelos, utilizou-se o software estatístico Stata/SE for Windows. Cabe destacar que o modelo econométrico proposto para analisar a possível relação existente em custos de capital e nível de disclosure adotou os procedimentos usuais de validação das inferências, efetuando o teste de fator de inflação das variâncias com o intuito de verificar se as variáveis são colineares.

Por fim, aplicaram-se os seguintes testes: de Chow (Teste F), para avaliar a utilização de Efeitos fixos versus Pooled; de Breusch-Pagan, para verificar a utilização do modelo de Efeitos Aleatórios versus Polled; de Hausman, para verificar se os coeficientes de Efeitos Fixos e Efeitos Aleatórios são sistematicamente diferentes, uma vez que o estimador de efeitos fixos é consistente, independentemente, da correlação entre o componente não observável e as variáveis explicativas; e, por último, foram aplicados os testes de Wooldrigde, para verificar problemas de autocorrelação, e de Wald, que testa o problema de heterocedasticidade.

\subsection{Limitações da Pesquisa}

A primeira delimitação deste estudo está relacionada à definição operacional da variável de índice de disclosure. Tal variável foi definida como a pontuação atribuída a cada entidade de acordo com a abrangência das informações presentes nos demonstrativos contábeis das empresas que foram objetos deste estudo.

Outro ponto de limitação refere-se à amostra em que das 100 empresas selecionadas, excluem-se as organizações que apareceram em dois momentos no índice IBRx-100, uma vez que apresentavam os mesmos 
dados, essa primeira exclusão totalizou em 16 companhias. Do total de 100 empresas, foram selecionadas 84 empresas.

Ressalta-se que, a partir da análise do box plot, optou-se por desconsiderar as empresas que possuíam observações extremas (outliers), situadas na ponta superior e inferior da distribuição, totalizando 18 empresas. A incorporação desse procedimento de eliminação objetivou proporcionar maior consistência e robustez aos resultados.

Vale ressaltar que a amostra utilizada nesta pesquisa, apesar de ser representativa, foi obtida em um espaço temporal limitado. A quantidade de variáveis utilizadas para mensurar o custo de capital das empresas também é uma limitação importante. Outra restrição, diz respeito às variáveis externas. Nesta pesquisa, foram adotados apenas o PIB e a Taxa de Inflação, pressupondo-se que podem ser analisadas outras variáveis externas que venham influenciar a variável explicada neste estudo.

\section{ANÁLISE DOS RESULTADOS}

Como o objetivo deste trabalho foi analisar a relação entre nível de disclosure e o custo de capital das empresas de capital aberto, após a conversão das normas contábeis brasileiras para os IFRS, foram gerados quatro diferentes tipos de modelos de regressão com dados em painel para cada variável explicada em que o primeiro modelo mediu as variáveis entre os anos de 2005 até 2011.

No segundo modelo criou-se uma variável dummy para ser acrescentada às demais variáveis, atribuindose o valor 1 para o caso em que a empresa adota os IFRS para elaboração das demonstrações financeiras, e 0 quando a empresa não adota as normas internacionais de contabilidade visualizando em cada empresa presença ou não dessa informação durante os anos de 2005 até 2011.

O terceiro modelo foi gerado entre os anos de 2005 até 2007, período no qual as empresas não necessitavam elaborar os demonstrativos contábeis utilizando os padrões das normas internacionais de contabilidade.

Porém o quarto modelo de regressão com dados em painel considerou o período de 2008 até 2011, em que a partir de 2008 com a alteração da lei de número 6.404/76 pela lei 11.638/07 as empresas brasileiras de capital aberto foram orientadas a elaborar suas demonstrações contábeis seguindo o processo de conversão para as normas internacionais de contabilidade.

\subsection{Análise dos modelos de regressão utilizados para estimar o Custo de Capital Próprio}

Antes de estimar os modelos de regressão calcularam-se os coeficientes de determinação e de determinação ajustado, cujos valores se comportaram conforme demonstrado através da Tabela 1.

Tabela 1. Coeficientes de determinação $\left(r^{2}\right)$ e determinação ajustado $\left(R^{2}\right)$

dos quatro modelos de regressão elaborados para estimação do Custo de Capital Próprio

\begin{tabular}{c|c|c|c}
\hline Custo do Capital Próprio (Ke) & $r^{2}$ & $R^{2}$ & Prob $>$ F \\
\hline Modelo 1: sem a variável dummy IFRS (2005 a 2011) & 0,1188 & 0,1063 & 0,0000 \\
\hline Modelo 2: com a variável dummy IFRS (2005 a 2011) & 0,1198 & 0,1051 & 0,0000 \\
\hline Modelo 3: antes da conversão para os IFRS (2005 a 2007) & 0,3657 & 0,3430 & 0,0000 \\
\hline Modelo 4: após a conversão para os IFRS (2008 a 2011) & 0,0715 & 0,0488 & 0,0055 \\
\hline
\end{tabular}

Fonte: Elaborado pelos autores

Os valores dos coeficientes de determinação demonstraram que o modelo 3 possui um maior valor de $37 \%$ explicação das variáveis selecionadas para a estimação do custo do capital das empresas selecionadas da 
amostra, contudo o modelo 4 apresentou um menor valor do coeficiente de determinação ajustado igualando-se a $4,88 \%$ de explicação. Salienta-se que todos os valores dos coeficientes de determinação estão dentro de um nível de significância de 5\%, considerando uma curva de distribuição normal.

A validação dos modelos de regressão foi realizada pela aplicação dos testes conforme demonstrado através da Tabela 2.

Tabela 2. Resultados dos testes de validação dos modelos para estimação do Custo de Capital Próprio

\begin{tabular}{c|c|c|c|c|c}
\hline $\begin{array}{c}\text { Custo do Capital } \\
\text { Próprio (Ke) }\end{array}$ & $\begin{array}{c}\text { Fator de Inflação da } \\
\text { Variância (FIV) }\end{array}$ & Chow (Teste F) & $\begin{array}{c}\text { Breusch- } \\
\text { Pagan }\end{array}$ & Hausman & $\begin{array}{c}\text { Modelo Final } \\
\text { Escolhido }\end{array}$ \\
\hline $\begin{array}{c}\text { Modelo 1: sem a } \\
\text { variável dummy IFRS } \\
(2005 \text { a 2011) }\end{array}$ & 1,29 & 0,0000 & 0,0000 & 0,7013 & Efeitos Aleatórios \\
\hline $\begin{array}{c}\text { Modelo 2: com a } \\
\text { variável dummy IFRS } \\
(2005 \text { a 2011) }\end{array}$ & 1,35 & 0,0000 & 0,0000 & 0,7459 & Efeitos Aleatórios \\
\hline $\begin{array}{c}\text { Modelo 3: antes da } \\
\text { conversão para os } \\
\text { IFRS (2005 a 2007) }\end{array}$ & 1,32 & 0,0000 & 0,0000 & 0,8270 & Efeitos Aleatórios \\
\hline $\begin{array}{c}\text { Modelo 4: após a } \\
\text { conversão para os }\end{array}$ & 1,54 & 0,0000 & 0,0000 & 0,2787 & Efeitos Aleatórios \\
\hline IFRS (2008 a 2011)
\end{tabular}

Fonte: Elaborado pelos autores

Ao verificar os valores de inflação das variâncias pela Tabela 9 os quatro modelos estudados não apresentaram problema de multicolinearidade sendo que a média desses valores não foi superior a 1,6, dessa forma, as variáveis do modelo apresentaram uma baixa relação linear. De acordo com o valor dos testes de Hausman recomenda-se utilizar o modelo de efeitos aleatórios para os quatro modelos. Os testes de autocorrelação, e de heterocedasticidade encontrados se comportaram conforme a Tabela 3.

Tabela 3: Resultados dos testes de Wooldrigde e Wald dos modelos para estimação do Custo de Capital Próprio

\begin{tabular}{c|c|c|c}
\hline Custo do Capital de Próprio (Ke) & Wooldrigde & Wald & Modelo Final \\
\hline $\begin{array}{c}\text { Modelo 1: sem a variável dummy IFRS (2005 } \\
\text { a 2011) }\end{array}$ & 0,0001 & 0,0000 & $\begin{array}{c}\text { Efeitos Aleatórios Autocorrelacionado e } \\
\text { Heterocedástico }\end{array}$ \\
\hline $\begin{array}{c}\text { Modelo 2: com a variável dummy IFRS (2005 } \\
\text { a 2011) }\end{array}$ & 0,0001 & 0,0000 & $\begin{array}{c}\text { Efeitos Aleatórios Autocorrelacionado e } \\
\text { Heterocedástisco }\end{array}$ \\
\hline $\begin{array}{c}\text { Modelo 3: antes da conversão para os IFRS } \\
\text { (2005 a 2007) }\end{array}$ & 0,9833 & 0,0000 & $\begin{array}{c}\text { Efeitos Aleatórios não Autocorrelacionado e } \\
\text { Heterocedástisco }\end{array}$ \\
\hline $\begin{array}{c}\text { Modelo 4: após a conversão para os IFRS } \\
\text { (2008 a 2011) }\end{array}$ & 0,9955 & 0,0000 & $\begin{array}{c}\text { Efeitos Fixos não Autocorrelacionado e } \\
\text { Heterocedástisco }\end{array}$ \\
\hline
\end{tabular}

Fonte: Elaborado pelos autores

A Tabela 4 apresenta e compara os modelos escolhidos entre os anos de 2005 até 2011 para a estimação do custo de capital próprio. 
Tabela 4. Modelos escolhidos entre os anos de 2005 até 2011

\begin{tabular}{|c|c|c|c|c|c|}
\hline \multicolumn{3}{|c|}{$\begin{array}{c}\text { Custo do Capital Próprio (Ke) sem a variável Dummy } \\
\text { IFRS }\end{array}$} & \multicolumn{3}{|c|}{ Custo do Próprio (Ke) com a variável Dummy IFRS } \\
\hline \multicolumn{3}{|c|}{ Modelo de Efeitos Aleatórios } & \multicolumn{3}{|c|}{ Modelo de Efeitos Aleatórios } \\
\hline Variáveis & Coeficientes & Valor $\mathrm{P}>\mathrm{z}$ & Variáveis & Coeficientes & Valor $\mathrm{P}>\mathrm{z}$ \\
\hline${ }_{(\text {Constante) }}$ & $-0,0154372$ & 0,477 & $\beta_{0 i t}($ Constante $)$ & $-0,0407603$ & 0,068 \\
\hline Índice de Disclosure & $-0,0000762$ & 0,990 & Índice de Disclosure & $-0,0001933$ & 0,974 \\
\hline $\begin{array}{c}\text { Nível de } \\
\text { Endividamento }\end{array}$ & 0,1481804 & 0,000 & $\begin{array}{c}\text { Nível de } \\
\text { Endividamento }\end{array}$ & 0,1414031 & 0,000 \\
\hline Alavancagem & 0,0031967 & 0,328 & Alavancagem & 0,0038451 & 0,226 \\
\hline Tamanho da Empresa & $-0,0459585$ & 0,734 & Tamanho da Empresa & 0,1063716 & 0,447 \\
\hline PIB & $-0,0712517$ & 0,086 & PIB & 0,0659798 & 0,099 \\
\hline Taxa de Inflação & 0,1798097 & 0,115 & Taxa de Inflação & 0,3009867 & 0,010 \\
\hline- & - & - & IFRS (variável dummy) & $-0,0085885$ & 0,009 \\
\hline
\end{tabular}

Fonte: Elaborado pelos autores

De acordo com os resultados demonstrados por meio da Tabela 4, o índice de disclosure apresentou valores negativos para a estimação do custo do capital próprio, contudo, conforme os níveis de significância apresentados, o índice de disclosure não afeta o custo de capital próprio das empresas, nos dois modelos selecionados.

Nos modelos selecionados apenas as variáveis nível de endividamento e IFRS apresentaram-se significativas considerando $5 \%$ de aceitação, com a variável nível de endividamento contribuindo para o aumento do custo de capital uma vez que os valores dos coeficientes nos dois modelos foram positivos, porém a variável IFRS apresentou valor negativo contribuindo para a redução do custo de capital próprio.

Esses resultados também estão de acordo com a hipótese nula em que o nível de divulgação das informações contábeis após a conversão dos IFRS não impacta o custo de capital próprio da amostra de empresas analisadas nesta pesquisa.

Tabela 5. Modelos escolhidos antes e após a conversão para os IFRS referentes ao Custo de Capital Próprio

\begin{tabular}{|c|c|c|c|c|c|}
\hline \multicolumn{3}{|c|}{$\begin{array}{l}\text { Custo do Capital Próprio (Ke) antes da conversão para os IFRS } \\
\text { (2005 a 2007) }\end{array}$} & \multicolumn{3}{|c|}{$\begin{array}{l}\text { Custo do Próprio (Ke) após a conversão para os IFRS } \\
\qquad(2008 \text { a 2011) }\end{array}$} \\
\hline \multicolumn{3}{|c|}{ Modelo de Efeitos Aleatórios } & \multicolumn{3}{|c|}{ Modelo de Efeitos Aleatórios } \\
\hline Variáveis & Coeficientes & Valor $\mathrm{P}>\mathrm{z}$ & Variáveis & Coeficientes & Valor $\mathrm{P}>\mathrm{z}$ \\
\hline$\underset{\text { (Constante) }}{\beta_{0 i t}}$ & $-0,010632$ & 0,741 & $\beta_{0 \dot{t}}$ (Constante) & $-0,000145$ & 0,609 \\
\hline Índice de Disclosure & 0,0250125 & 0,024 & Índice de Disclosure & $-3,06006$ & 0,860 \\
\hline $\begin{array}{c}\text { Nível de } \\
\text { Endividamento }\end{array}$ & 0,0387985 & 0,106 & $\begin{array}{c}\text { Nível de } \\
\text { Endividamento }\end{array}$ & 0,0000212 & 0,724 \\
\hline Alavancagem & 0,0101319 & 0,081 & Alavancagem & $-0,0000104$ & 0,642 \\
\hline Tamanho da Empresa & 0,2419297 & 0,174 & Tamanho da Empresa & 0,0006404 & 0,607 \\
\hline PIB & $-0,4312233$ & 0,023 & PIB & $-0,0002876$ & 0,627 \\
\hline Taxa de Inflação & 0,2560986 & 0,258 & Taxa de Inflação & 0,000145 & 0,613 \\
\hline
\end{tabular}

Fonte: Elaborado pelos autores 
De acordo com os resultados demonstrados por meio da Tabela 5, o índice de disclosure influenciou o custo de capital próprio antes da conversão para o padrão IFRS, uma vez que o valor de probabilidade está dentro de um nível de aceitação $2,4 \%$ contribuindo para a elevação do custo de capital de acordo com o sinal positivo encontrado no coeficiente da variável. Porém, nos resultados encontrados no modelo após a adoção do padrão IFRS o valor da variável índice disclosure não impacta o custo de capital uma vez que valor de probabilidade apresentou-se dentro de uma área de rejeição.

É importante salientar que no modelo após a conversão nenhuma variável apresentou-se significativa, estando todas dentro de uma área de rejeição considerando intervalos de confiança de $95 \%$ e $90 \%$ respectivamente. Deve ser ressaltado que a regressão que mediu os dados entre os anos 2005 e 2007, apresentou as variáveis alavancagem e PIB dentro de uma área de aceitação, em que o PIB foi aceito com 95\% de confiança contribuindo para a redução do custo de capital e a alavancagem foi aceita com $90 \%$ de confiança contribuindo para o aumento do custo de capital próprio.

\subsection{Comparação dos resultados com pesquisas realizadas anteriormente}

Os resultados desta pesquisa estão de acordo com a hipótese nula em que o nível de divulgação das informações contábeis após a conversão dos IFRS não impacta o custo de capital próprio da amostra de empresas analisadas nesta pesquisa e podem ser comparados com os estudos internacionais de Botosan (1997) que examinou a associação entre custo de capital e o nível de disclosure. Para firmas que atraem baixo nível de reporte por parte dos analistas de mercado, maior disclosure está associado com menor custo de capital. Já para as firmas mais reportadas pelos analistas, a autora não encontrou evidência de associação, e justifica que talvez isso tenha ocorrido por basear-se apenas em relatórios anuais.

Outro estudo de Botosan e Plumlee (2001), em um reexame da questão, apurou que existe associação negativa entre custo de capital e o nível de disclosure anual, mas uma associação positiva com disclosure mais tempestivo. As autoras ressaltaram que, embora este último achado possa contrariar a teoria, ele vem ao encontro das reclamações dos administradores das empresas, de que a informação mais tempestiva aumenta o custo de capital, e elas atribuem a explicação desse fenômeno a um provável aumento na volatilidade dos preços.

A pesquisa de Hail (2002) utilizou um procedimento semelhante e encontrou no exame da amostra de 73 firmas suíças não financeiras uma associação negativa e altamente significativa entre as duas variáveis. Chen, Chen e Wei (2003) testaram a relação no mercado asiático, acrescentando à questão outros indicadores de governança corporativa, tendo encontrado que tanto o disclosure quanto os indicadores de governança não relacionados ao disclosure reduzem o custo de capital. Francis, Khurana e Pereira (2003) estudaram empresas de 34 países, pertencentes a 18 setores industriais, com o objetivo de verificar a relação entre o nível de disclosure voluntário fora dos EUA e a necessidade de financiamento externo. Além de verificarem uma correlação positiva entre as duas variáveis, os pesquisadores encontraram também que as firmas com maior nível de disclosure têm menor custo de capital.

No cenário brasileiro destaca-se as pesquisas de Bruni (2002) que examinou o comportamento das ações das empresas brasileiras emissoras de ADR no período 1992 a 2001, evidenciou uma significativa redução do custo de capital próprio, expresso pela variação negativa dos betas das ações, após a emissão dos ADRs.

Silveira (2003) investigou se as empresas brasileiras com ações negociadas em bolsa e que emitiram ADR na década de 90 passaram por significativa modificação em seu custo de capital. Os resultados encontrados sugerem que, em média, as empresas apresentaram redução em seu custo de capital.

Alencar (2005), verificou se existe relação entre nível de disclosure e custo de capital nas empresas brasileiras e os resultados encontrados possibilitou concluir que o nível de disclosure não influencia o custo de capital das empresas do mercado brasileiro.

Os resultados da pesquisa de Nakamura et al. (2006) evidenciaram que o modelo escolhido possui uma associação negativa da variável disclosure e do cálculo do custo de capital conforme os resultados obtidos nos testes empíricos.

Fernandes (2012) encontrou evidencias em seu estudo de que, no mercado brasileiro, o disclosure voluntário não afeta o custo de capital. Cazzari e Lima (2012) concluíram também em seu artigo que o nível de divulgação das informações contábeis das empresas que fazem parte do Índice de Carbono Eficiente não afeta o 
custo de capital destas organizações.

Gonçalves et al. (2013), evidenciaram em seus estudos que as informações sociais são capturadas pelo mercado e influenciam a precificação das ações, corroborando a versão semiforte de eficiência de mercado, que se refere à incorporação aos preços das ações e, consequentemente, aos retornos das informações disponíveis (passadas e presentes), de forma eficiente.

\section{CONCLUSÕES}

O objetivo deste estudo foi analisar o nível de disclosure e sua relação com o custo de capital próprio das empresas de capital aberto, após a convergência das normas contábeis brasileiras para os IFRS.

A análise dos dados corrobora a resposta da questão formulada neste trabalho, demonstrando não existirem evidências estatísticas de que o nível de disclosure tem relação com o custo do capital, após a conversão para as normas internacionais de contabilidade.

A amostra selecionada abrangeu as empresas que compõem o índice IBrx 100 que representa as 100 maiores companhias listadas na bolsa, sendo selecionadas apenas 66 organizações para a condução deste estudo, uma vez que se optou por trabalhar com dados em painel não balanceado, e o período selecionado para a coleta de dados compreende o ano de 2005 até 2011, perfazendo um total de 7 anos.

Para atingir o objetivo proposto, aplicou-se o método de regressão com dados em painel, com a finalidade de escolher um, dentre os três principais modelos, Pooled, Efeitos Fixos e Efeitos Aleatórios, que fosse mais adequado para demonstrar se e de que forma o nível de disclosure afeta o custo de capital das empresas. A escolha do modelo ocorreu em virtude dos resultados encontrados nos testes de Chow, Breusch Pagan e Hausman, que foram utilizados para determinar qual modelo foi mais apropriado.

As conclusões encontradas de acordo com a análise dos resultados estão de acordo com a hipótese deste estudo, a qual mencionava que o nível de divulgação das informações contábeis não impactava o custo de capital das empresas, e em outro momento da análise está de acordo com uma das hipóteses alternativas que afirma que o nível de disclosure contribui para a redução do capital das empresas analisadas nesta pesquisa.

Vale ressaltar que essa conclusão não deve ser generalizada em virtude do fato de que a amostra utilizada nesta pesquisa, apesar de ser representativa, foi obtida em um espaço temporal limitado, e da baixa quantidade de variáveis utilizadas para mensurar o custo de capital das empresas. Com isso, existe a possibilidade de que, aumentando-se o espaço de tempo e a quantidade de variáveis, as conclusões aqui apresentadas possam sofrer alterações.

Considerando-se os resultados encontrados, a principal limitação desta pesquisa está associada à heterogeneidade das empresas componentes da amostra, seja com relação aos setores em que as mesmas atuam ou pelo fato de que as práticas de governança corporativa tenham sofrido alterações durante o período analisado.

Outra restrição, referente às conclusões aqui exteriorizadas, diz respeito às variáveis externas. Nesta pesquisa, foram adotadas apenas o PIB e a Taxa de Inflação, pressupondo-se que podem ser analisadas outras variáveis externas que venham influenciar a variável explicada neste estudo. Portanto, essas limitações possibilitam a realização de novos estudos que abordem outras variáveis para medir o custo de capital, juntamente, com novos modelos de disclosure, bem como aumentar o período estudado, com o objetivo de alcançar maior robustez das análises e conclusões aqui apresentadas.

Sendo assim, propõe-se, a título de sugestão para futuras pesquisas, que um estudo dessa natureza seja realizado para medir a qualidade do índice de disclosure com uma amostra maior de empresas, com dados trimestrais e com a inclusão de mais variáveis exógenas, com o intuito de que se possa explicar melhor o custo de capital das organizações. 


\section{REFERÊNCIAS}

AKERLOF, George A. The market for "Lemons": quality uncertainty and the market mechanism. The Quarterly Journal of Economics. Cambridge: v. 84, n. 3, p. 488-500, aug. 1970.

ALENCAR, Roberta Carvalho de. Custo do capital próprio e o nível de Disclosure nas empresas brasileiras. Brazilian Business Review. Vitória, v. 2, n.1, p. 01-12, jan./jun. 2005.

. Nível de disclosure e custo de capital próprio no mercado brasileiro. 2007. 104 f. Tese (Doutorado em Ciências Contábeis)-Departamento de Contabilidade e Atuária da Faculdade de Economia, Administração e Contabilidade, Universidade de São Paulo, São Paulo, 2007.

ALENCAR, Roberta Carvalho de; LOPES, Alexsandro Broedel. Custo do Capital Próprio e Nível de Disclosure nas Empresas Brasileiras. In: $5^{\circ}$ CONGRESSO USP DE CONTROLADORIA E CONTABILIDADE, 2005, São Paulo. Anais... São Paulo: USP, 2005.

ANDRADE, Lélis Pedro de; SALAZAR, German Torres, CALEGÁRIO, Cristina Lélis Leal; SILVA, Sabrina Soares da. Governança corporativa: uma análise da relação do conselho de administração com o valor de mercado e desempenho das empresas brasileiras. Revista de Administração Mackenzie, v. 10, p. 4-31, jul./ ago. 2009 .

ASSAF NETO, Alexandre; LIMA, Fabiano Guasti; ARAÚJO, Adriana Maria Procópio de. Uma proposta metodológica para o cálculo do custo de capital no Brasil. Revista de Administração, USP, São Paulo, v. 43, n. 1, p. 72-83, 2008.

BOtOSAN, Christine A. Disclosure level and the cost of equity capital. The Accounting Review. Sarasota: v. 72 , n. 3, p. 323-349, 1997.

BOTOSAN, Christine A.; PLUMLEE Marlene A. Estimating expected cost of capital: atheory-based approach. Working Paper. SSRN, 2001

BRUNI, Adriano Leal. Globalização financeira, eficiência informacional e custo de capital: uma análise das emissões de ADRs brasileiros no período 1992-2001. 2002. 188 f. Tese (Doutorado em Administração)Faculdade de Economia, Administração e Contabilidade, Universidade de São Paulo, São Paulo, 2002.

CAZZARI, Roberto Bomgiovani; LIMA, Iran Siqueira. A relação entre empresas que participam do ICO $^{2}$ e o custo de capital próprio. In: CONGRESSO USP DE CONTROLADORIA E CONTABILIDADE, 12, São Paulo. Anais... São Paulo: USP, 2012.

CHEN, Kevin C.W.; CHEN, Shilong; WEI K. C. John. Disclosure, Corporate governance, and the Cost of Equity Capital: evidence from Asias Emerging Markets. Working Paper, SSRN. jun. 2003.

CORMIER, Denis; GORDON, Irene M.; MAGMAN, Michaelb. Corporate environmental disclosure: contrasting management's perceptions with reality. Journal of Business Ethics, v. 49, n. 2, p. 143-165, 2004

DEEGAN, Craig; RANKIN, Michaela. The materiality of environmental information to users of annual reports. Accounting, Auditing \& Accountability Journal, v. 10, n. 4, p. 562-583, 1997.

DIAS FILHO, José Maria. A Linguagem Utilizada na Evidenciação Contábil: uma análise de sua compreensibilidade à luz da teoria da comunicação. Caderno de Estudos (USP), São Paulo, v. 13, n. 24, p. 38-49, jul./dez. 2000.

DYE, Ronald. An evaluation of "essays on disclosure" and the disclosure literature in accounting. Journal of Accounting and Economics, v. 32, p. 181-235, 2001.

FERNANDES, Sheila Mendes. Nível de disclosure ambiental das empresas brasileiras listadas na Bm\&fBovespa: uma análise do período de 2006 a 2010. Revista de Gestão Social e Ambiental - RGSA, São Paulo, v. 6, n. 2, p. 106-120, maio/ago. 2012.

FRANCIS, Jere R. KHURANA, Inder K. PEREIRA, Raynolde. Global evidence on incentives for voluntary accounting disclosures and the effect on cost of capital. Working Paper, SSRN. September. 2003.

GUJARATI, Damodar N.; PORTER, Dawn C. Econometria básica. 5. ed. São Paulo: Mcgrawhill Bookman, 2011.

GONÇALVES, Rodrigo de Souza; MEDEIROS, Otávio Ribeiro de; NIYAMA, Jorge Katsumi; WEFFORT, Elionor Farah Jreige. Social Disclosure e custo de Capital Próprio em companhias abertas no Brasil. Revista 
de Contabilidade \& Finanças da USP. São Paulo, v. 24, n. 62, p. 113-124, maio/ago. 2013.

HAIL, Luzi. The impact of voluntary corporate disclosures on the ex-ante cost of capital. The European Accounting Review, v. 11, n. 4, p. 741-773, 2002.

HASSELDINE, J.; SALAMA, A. I. TOMS, J. S.. Quantity versus quality: the impact of environmental disclosures on the reputations of UK Plcs. The British Accounting Review, v. 37, n. 2, p. 231-248, 2005.

LIMA, Gerlando Augusto Sampaio Franco de. Utilização da teoria de divulgação para a avaliação da relação do nível de Disclosure com o custo da dívida das empresas brasileiras. 2007. 118 f. Tese (Doutorado em Controladoria e Contabilidade)-Faculdade de Economia Administração e Contabilidade, Universidade de São Paulo, São Paulo, 2007.

Nível de evidenciação x custo da dívida das empresas brasileiras. Revista de Contabilidade \& Finanças da USP. São Paulo, v. 20, n. 49, p. 95-108, jan./abril. 2009.

NAKAMURA, Wilson Toshiro; GOMES, Elizabeth Alves; ANTUNES, Maria Thereza Pompa; MARÇAL, Émerson Fernandes. Estudo sobre os níveis de disclosure adotados pelas empresas brasileiras e seu impacto no custo de capital. In: ENANPAD, 30., 2006, Salvador-BA. Anais..., 2006

PONTE, Vera Maria Rodrigues; OLIVEIRA, Marcelle Colares; MOURA, Héber; CARMO, Renata Coelho de Almeida. Análise das Práticas de Evidenciação de Informações Avançadas e Não-obrigatórias nas Demonstrações Contábeis das Empresas Brasileiras: um estudo comparativo dos exercícios de 2002 e 2005. Revista Contabilidade e Finanças - USP, v. 18, p. 50-62, set./dez. 2007.

ROVER, Suliani; BORBA, José Alonso; MURCIA, Fernando Dal Ri. Características do disclosure ambiental de empresas brasileiras potencialmente poluidoras: análise das demonstrações financeiras e dos relatórios de sustentabilidade do período de 2005 a 2007. Revista Contemporânea de Economia e Gestão. v.7, p. 23-36, jan./jun. 2009.

SALOTTI, Bruno Meirelles; YAMAMOTO, Marina Mitiyo. Ensaio sobre a teoria da divulgação. Brazilian Business Review. v. 2, n. 1, p. 53-70, jan./jun. 2005.

SILVA, Davy Antonio da; REIS, Elizio Marcos dos; LAMOUNIER, Wagner Moura. O processo de criação de valor para o acionista comparado em cada nível de governança corporativa segmentado na BOVESPA: um estudo com as empresas que compõe a carteira de ações do Índice Brasil (IBrX 100). Sociedade Contabilidade e Gestão, Rio de Janeiro, v. 7, n. 1, jan./jun. 2012.

SILVA, L. S. A; QUELHAS, O. L. G. Sustentabilidade Empresarial e o Impacto no Custo de Capital Próprio das Empresas de Capital Aberto. Gestão \& Produção, v. 13, 385-395, 2006.

SILVEIRA, Heber P. Internacionalização e custo de capital das empresas brasileiras: análise do impacto da emissão de american depositary receipts. 2003. 131 f. Dissertação (Mestrado em Ciências Contábeis)Faculdade de Economia e Administração, Universidade de São Paulo, São Paulo, 2003.

SOARES, A. H.. Balanços se sofisticaram para atrair investidor estrangeiro. Gazeta Mercantil: caderno finanças e mercados. São Paulo, 2001.

STOCK, James H.; WATSON, Mark W. Econometria. São Paulo, Pearson, 2004.

TILT, Carol Ann. The content and disclosure of Australian corporate environmental policies. Accounting, Auditing \& Accountability Journal, v. 14, n. 2, p. 190-212, 2001.

VERRECHIA, Robert E. Essays on disclosure. Journal of Accounting and Economics. Amsterdam: v. 32, n. 1-3, p. 97-180, dez. 2001.

YAMAMOTO, Marina Mitiyo; SALOTTI, Bruno Meirelles. Informação contábil. São Paulo: Atlas, 2006. 